\title{
Tannerella forsythia is associated with increased levels of atherogenic low density lipoprotein and total cholesterol in chronic periodontitis
}

\author{
Carlos M. Ardila ${ }^{1}$, Aide-Yancelly Perez-Valencia ${ }^{2}$, Willer-Leandro Rendon-Osorio ${ }^{2}$ \\ ${ }^{1}$ Periodontist. Ph.D in Epidemiology, Biomedical Stomatology Group, Universidad de Antioquia U de A, Medellín, Colombia, \\ Department of Periodontology, School of Dentistry, Universidad de Antioquia \\ ${ }^{2}$ Dentist, Department of Periodontology, School of Dentistry, Universidad de Antioquia
}

Correspondence:

Calle 70 No. $52-21$

Medellin, Colombia

martin.ardila@udea.edu.co

Received: 16/10/2014

Accepted: 05/02/2015

Ardila CM, Perez-Valencia AY, Rendon-Osorio WL. Tannerella forsythia is associated with increased levels of atherogenic low density lipoprotein and total cholesterol in chronic periodontitis. J Clin Exp Dent. 2015;7(2):e25460.

http://www.medicinaoral.com/odo/volumenes/v7i2/jcedv7i2p254.pdf

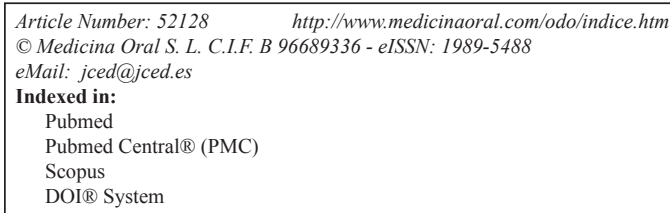

\begin{abstract}
Background: Accumulating evidence suggests that acute and chronic infections with periodontopathogens are associated with an increased risk of cardiovascular disease. The objective of this study was to assess whether Tannerella forsythia and Porphyromonas gingivalis are associated with increased levels of atherogenic low-density lipoprotein (LDL), high-density lipoprotein, total cholesterol (TC), triglycerides and body mass index (BMI) in chronic periodontitis patients.

Material and Methods: Medical history and clinical and radiographic examination were conducted in 80 chronic periodontitis patients and 28 healthy individuals. Fasting blood samples were drawn for the measurement of the parameters of dyslipidemia. Anthropometric measurements such as height in meters and weight in kilograms were recorded. Both periodontitis and control subjects were asked to answer a questionnaire with regard to their sociodemographic and smoking status. The presence of $T$. forsythia, and P. gingivalis was detected using primers designed to target the respective $16 \mathrm{~S}$ rRNA gene sequences.

Results: The occurrence of T. forsythia and P. gingivalis was higher in the group of subjects with periodontitis. Superior levels of triglycerides were observed in chronic periodontitis patients compared to healthy individuals. High levels of TC in periodontitis persons were significantly associated with increased bleeding on probing. Greater mean levels of TC and LDL were shown in the presence of $T$. forsythia $(P<0.05)$. Likewise, higher proportions of patients with BMI $\geq 25 \mathrm{~kg} / \mathrm{m}^{2}$ related with $T$. forsythia $(P<0.05)$. T. forsythia was a significant discriminating factor in the multivariate linear regression model emerging as significant explanatory of increased levels of TC $(\beta=17,879,95 \% \mathrm{CI}=4,357-31,401 ; p=0.01)$ and $\operatorname{LDL}(\beta=17,162,95 \% \mathrm{CI}=4,009-30,316 ; p=0.01)$.

Conclusions: Higher levels of serum total cholesterol and LDL were observed in the occurrence of T. forsythia and the presence of this periodontopathogen may increase the atherogenic potency of low-density lipoprotein that may augment the risk for atherosclerosis in periodontal disease patients.
\end{abstract}

Key words: Periodontitis, dyslipidemia, Tannerella forsythia, cardiovascular disease. 


\section{Introduction}

Dyslipidemia is recognized as one of the major modifiable risk factors for coronary heart disease. Nevertheless, some patients with atherosclerosis lack presently of recognized risk factors including hypertension, hypercholesterolemia, diabetes and smoking, suggesting the occurrence of other causative mechanisms (1). Thus, infectious agents signify a main resource of systemic inflammatory reaction with the possibility to step up plaque growth and instability (2). Accumulating evidence suggests that acute and chronic infections with periodontopathogens are associated with an increased risk of cardiovascular disease (3). The susceptibility of the arterial wall to bacterial infection is increased in the existence of other cardiovascular risk factors, such as dyslipidemia, suggesting that chronic infection may incline an individual to atherosclerosis (4).

Among the microorganisms observed in atherosclerotic vessels, Porphyromonas gingivalis does not emerge leading and it is infrequently detected without the occurrence of other organisms (5), which highlights the magnitude of studying how polymicrobial infection influences atherosclerosis development. Tannerella forsythia has remained an under investigated organism because of its fastidious growth and recalcitrant nature to genetic manipulation (6). Similarly to $P$. gingivalis, $T$. forsythia has been detected in human clinical atherosclerotic plaque lesions (7). Therefore, it is also important to study the relationship of the presence of these two microorganisms with dyslipidemia. Previous investigations showed that periodontitis is associated with increased levels of lowdensity lipoprotein (LDL), total cholesterol (TC), and triglycerides (TGs) $(8,9)$. Similarly, as pointed out by Tu et al. (10), periodontitis patients had higher levels of body mass index (BMI) compared to healthy controls. Conversely, it was shown that periodontitis decreases the level of high-density lipoprotein (HDL) (10-13).

To our knowledge no studies have looked the influence of T. forsythia on the levels of LDL, HDL, TC, TGs and BMI. Thus, the objective of this study was to assess whether T. forsythia and P. gingivalis are associated with augmented levels of atherogenic LDL, HDL, total cholesterol, triglycerides and body mass index.

\section{Material and Methods}

-Patient selection

Patients with a diagnosis of chronic periodontitis were considered candidates for the study. A total of 79 women and 29 men (aged 33 to 82 years) with $\geq 18$ residual teeth who attended the dental clinics of the Universidad de Antioquia in Medellín, Colombia were invited to participate in this study between January 2009 and December 2011. Of the 108 subjects included, 28 patients belonged to the control group (subjects without periodontitis).

The study design was approved by the Ethics Commit- tee on Human Research of the School of Dentistry of the University of Antioquia according to the Declaration of Helsinki on experimentation involving human subjects. Informed and written consent was obtained from each participant. Exclusion criteria included diagnosed diabetes and autoimmune diseases. Pregnant women, previous (six months) consumption of systemic antimicrobials, non-steroidal analgesics or anti-inflammatory drugs, and previous periodontal therapy also served as exclusion criteria.

-Clinical Evaluation

Clinical and radiographic examination and medical history were conducted for each person. The diagnosis of chronic periodontitis was made based on criteria defined by Eke et al. (14); subjects were classified as moderate periodontitis by $\geq 2$ interproximal sites with clinical attachment level (CAL) $\geq 4 \mathrm{~mm}$, or by $\geq 2$ interproximal sites with probing depth (PD) $\geq 5 \mathrm{~mm}$ (not at the same tooth). Severe periodontitis was characterized by $\geq 2$ interproximal sites with $C A L \geq 6 \mathrm{~mm}$ and $\geq 1$ inter-proximal site with $\mathrm{PD} \geq 5 \mathrm{~mm}$ (not at the same tooth). Subjects with no evidence of mild, moderate, or severe periodontitis were used as a control group.

A trained and calibrated clinician performed all clinical examinations. The intra-examiner reproducibility was assessed before and during the study. The intra-class correlation coefficients for mean PD and CAL was 0.92 and 0.91 , respectively; the intra-evaluator kappa index was in the range $0.85-0.96$. The presence or absence of bleeding on probing (BOP) and plaque were registered. PD and CAL were measured at all proximal, buccal and lingual surfaces to the nearest millimeter by a calibrated standard probe (UNC-15, Hu-Friedy, Chicago, IL).

The presence or absence of plaque was registered qualitatively. If bleeding occurred immediately after probing for pocket depth it was reported as positive. Probing depth is the distance between the gingival margin and to the bottom of the gingival pocket measured from six angles of each tooth. Gingival pockets $4 \mathrm{~mm}$ or deeper were considered to be pathogenic. CAL was determined at all sites by measuring the distance from the cementoenamel junction (CEJ) to the free gingival margin (GM), adding the PD at the same site. $\mathrm{CAL}=\mathrm{PD}+(\mathrm{CEJ}$ to GM) (all measurements in millimeters).

-Medical Examination

Fasting blood samples were drawn for the measurement of hemoglobin Alc (HbAlc), TC, HDL, LDL and TGs. The diagnosis of adipose tissue disorders was made according to the criteria defined by the Third Adult Treatment Panel of the National Cholesterol Education Program (15). To identify subjects with pathological values the following cut-off points were used: total cholesterol $\geq 200 \mathrm{mg} / \mathrm{dl} ; \mathrm{HDL}<40 \mathrm{mg} / \mathrm{dl}$ in men and $<50 \mathrm{mg} / \mathrm{dl}$ in women, respectively; low density lipoproteins (LDL) $\geq 130 \mathrm{mg} / \mathrm{dl}$; serum triglycerides $>150 \mathrm{mg} / \mathrm{dl}$ ); and body 
mass index $\left(\geq 25 \mathrm{~kg} / \mathrm{m}^{2}\right)$. Serum total cholesterol, HDL cholesterol, and triglyceride concentrations were determined by fully enzymatic methods in the same local laboratory of clinical chemistry. These values are applicable to individual with a normal risk for cardiovascular disease (15).

Anthropometric measurements such as height in meters and weight in kilograms were recorded. Body mass index was calculated using the formula BMI $=$ Weight $/$ Height (15).

Both periodontitis and control subjects were asked to answer a questionnaire with regard to their socio demographic and smoking status including gender (male/female), age (in years), smoking status (smoker/non smoker) and socioeconomic status (US $\geq 750$ income per month; yes/no).

-Microbial Sampling

Microbial sampling on periodontitis patients was performed on pockets $>5 \mathrm{~mm}$. The deepest six pockets were selected for sampling. After removing supragingival plaque with curette and isolating the area with cotton pellets, the paper points (Maillefer, Ballaigues, Switzerland) were inserted into each periodontal pocket for 20 seconds. One paper point from each site was introduced into an empty $1.5 \mathrm{ml}$ micro-fuge tube for polymerase chain reaction (PCR) analysis.

The presence of $T$. forsythia, and $P$. gingivalis was detected by PCR using primers designed to target the respective $16 \mathrm{~S}$ rRNA gene sequences, according to the method of Ashimoto et al. (16). Briefly, PCR mixtures $(50 \mathrm{~mL})$ were prepared with $5 \mathrm{~mL}$ of bacterial DNA (GoTaq Flexi DNA Polymerase, Promega), $0.5 \mathrm{mM}$ species-specific primers, $10 \mathrm{~mL}$ of 5 PCR buffer (Deoxynucleotide Triphosphates, Promega), 1.25 U of Taq DNA polymerase (Deoxynucleotide Triphosphates, Promega), $0.2 \mathrm{mMd}-$ NTP mix (Deoxynucleotide Triphosphates, Promega), and $1.5 \mathrm{mM} \mathrm{MgCl} 2$ (Promega). Gene-specific amplification was performed in a thermal cycler (MyCycler ${ }^{\circledR}$ Termal Cycler, Bio-Rad) with the following thermal profiles: T. forsythia and $P$. gingivalis, initial denaturation step at $95^{\circ} \mathrm{C}$ for 2 minutes, followed by 36 cycles of denaturation at $95^{\circ} \mathrm{C}$ for 30 seconds, annealing at $60^{\circ} \mathrm{C}$ for 1 minute and extension at $72^{\circ} \mathrm{C}$ for 1 minute, and a final extension at $72{ }^{\circ} \mathrm{C}$ for 2 minutes. PCR products were electrophoresed on $1 \%$ agarose gels and stained with $0.5 \mathrm{mg} / \mathrm{mL}$ ethidium bromide, and the presence of target bands for each bacterium was confirmed.

-Sample size calculation

The sample size was calculated with a power of $80 \%$ and a significance level of 0.05 (two-tailed) for detecting a risk ratio $\geq 2$ for a prevalence of TGs $>150 \mathrm{mg} / \mathrm{dl}$ of $70.83 \%$ and $29.17 \%$ (based on a previous study) (17) in the groups with and without periodontitis, respectively. Based on these calculations, it was determined that $\geq 22$ persons per group would be necessary.
-Statistical Analysis

Differences in continuous and categorical variables were examined with independent $t$ test (data were distributed normally) and $X^{2}$ test, respectively. Linear regression analysis was applied stepwise, and two final models were constructed for the dependent variable TC $(\mathrm{mg} / \mathrm{dl})$ and LDL (mg/dl), respectively. Variables included in the model were age (years), gender (male/female), smoking status (smoker/non smoker), socioeconomic status (US $\geq 750$ income per month; yes/no), presence of $P$. gingivalis (yes/ no), and T. forsythia (yes/no). Multicollinearity was not found during model fitting. Regression coefficients, standard errors, and adjusted $\mathrm{R}^{2}$ were expressed.

Besides, associations between BMI $\left(<25 \mathrm{~kg} / \mathrm{m}^{2}\right.$ versus $\geq 25 \mathrm{~kg} / \mathrm{m}^{2}$ ) and presence of $P$. gingivalis, and T. fors$y$ thia were assessed by logistic regression analysis. The odds ratio (OR) and corresponding 95\% confidence intervals (CI) was calculated. $P$ values of $<0.05$ were considered statistically significant. All analyses were performed using statistical software (SPSS version 18.0; SPSS, Chicago, IL).

\section{Results}

Eighteen women and ten men without periodontitis and 61 women and 19 men with chronic periodontitis were studied. The socio-demographic characteristics, periodontal parameters, body mass index and serum parameters of the patients with and without periodontitis are described in the table 1. The socio-demographic variables did not show statistically significant differences between the two groups, which make them comparable. There was a significant difference between both groups in relation to periodontal parameters. Similarly, the levels of TGs were higher in periodontitis patients compared to individuals without periodontitis (Table 1).

On the other hand, the proportion of occurrence of $T$. forsythia $(57.5 \%$ versus $28.5 \% ; P=0.008)$ and $P$. gingivalis $(76.2 \%$ versus $10.7 \%$; $P<0.0001)$ was higher in the group of patients with periodontitis.

Table 2 depicts the occurrence of pathologic lipid levels in the study subjects. Except for LDL, there were significant differences between both groups. An important finding of our work was that high levels of TC in periodontitis persons were significantly associated with increased BOP $(P<0.05)$.

With this information, we studied whether the presence of $T$. forsythia or $P$. gingivalis correlated with high mean levels of TC, TGs, HDL and LDL, using an independent $t$ test. Higher mean levels of TC and LDL were shown in presence of $T$. forsythia $(P<0.05)$ (Table 3$)$. Likewise, higher proportions of patients with $\mathrm{BMI} \geq 25 \mathrm{~kg} / \mathrm{m}^{2}$ related with $T$. forsythia $(P<0.05)$. Conversely, patients with or without presence of $P$. gingivalis did not present differences in the mean levels of the parameters of dyslipidemia. 
Table 1. Socio-demographic features, periodontal parameters, body mass index and lipids characters of the studied patients.

\begin{tabular}{|c|c|c|c|}
\hline Characteristic & Healthy persons & Periodontitis patients & $P$ value \\
\hline $\begin{array}{l}\text { Gender } \\
\% \text { Female } \\
\% \text { Male }\end{array}$ & $\begin{array}{l}64.28 \\
35.72\end{array}$ & $\begin{array}{l}76.25 \\
23.75\end{array}$ & $\begin{array}{l}\text { NS } \\
\text { NS }\end{array}$ \\
\hline Age (years \pm SD) & $45.9 \pm 6.4$ & $46 \pm 9.4$ & NS \\
\hline $\begin{array}{l}\text { Socioeconomic } \\
\text { Status } \geq \text { US } 750 \\
\text { Socioeconomic } \\
\text { Status }<\text { US } 750\end{array}$ & $\begin{array}{l}92 \% \\
8 \%\end{array}$ & $\begin{array}{l}92 \% \\
8 \%\end{array}$ & $\begin{array}{l}\text { NS } \\
\text { NS }\end{array}$ \\
\hline $\begin{array}{l}\text { Smoking } \\
\% \text { Non-smokers } \\
\% \text { Smokers }\end{array}$ & $\begin{array}{c}92.9 \\
7.1\end{array}$ & $\begin{array}{l}75 \\
25\end{array}$ & $\begin{array}{l}\text { NS } \\
\text { NS }\end{array}$ \\
\hline $\mathrm{CAL}(\mathrm{mm} \pm \mathrm{SD}$ & $1.8 \pm 0.3$ & $4.4 \pm 1.3$ & $P<0.0001$ \\
\hline $\mathrm{PD}(\mathrm{mm} \pm \mathrm{SD})$ & $1.7 \pm 0.3$ & $3.7 \pm 1.1$ & $P=0.002$ \\
\hline BOP & $25 \%$ & $50 \%$ & $P=0.002$ \\
\hline Plaque & $23 \%$ & $55 \%$ & $P=0.03$ \\
\hline BMI & $64 \%$ & $71 \%$ & NS \\
\hline TGs $(\mathrm{mg} / \mathrm{dl} \pm \mathrm{SD})$ & $165 \pm 76$ & $178 \pm 98$ & $P<0.05$ \\
\hline $\mathrm{HDL}(\mathrm{mg} / \mathrm{dl} \pm \mathrm{SD})$ & $50.4 \pm 17$ & $44 \pm 11.4$ & $P<0.05$ \\
\hline $\mathrm{TC}(\mathrm{mg} / \mathrm{dl} \pm \mathrm{SD})$ & $199 \pm 35$ & $200 \pm 36$ & NS \\
\hline $\mathrm{LDL}(\mathrm{mg} / \mathrm{dl} \pm \mathrm{SD})$ & $117 \pm 35$ & $123 \pm 28$ & NS \\
\hline
\end{tabular}

$\mathrm{SD}=$ standard deviation.

NS= Not significant association.

Table 2. Presence of blood lipids concentrations and BMI $25 \mathrm{Kg} / \mathrm{m}^{2}$ in the patients evaluated.

\begin{tabular}{|l|ccc|cc|c|}
\hline Lipid (mg/d) & \multicolumn{2}{|c|}{$\begin{array}{c}\text { Healthy } \\
\text { persons } \\
\text { n \% }\end{array}$} & \multicolumn{2}{c|}{$\begin{array}{c}\text { Periodontitis } \\
\text { patients } \\
\text { n \% }\end{array}$} & P value \\
\hline $\mathrm{BMI} \geq 25 \mathrm{~kg} / \mathrm{m}^{2}$ & 10 & 35.7 & 61 & 76.25 & 0.0001 \\
\hline $\mathrm{TGs}>150$ & 9 & 32.1 & 47 & 58.75 & $<0.05$ \\
\hline $\mathrm{HDL}<40$ & 5 & 17.8 & 32 & 40 & $<0.05$ \\
\hline $\mathrm{TC}>200$ & 7 & 25 & 43 & 53.75 & 0.008 \\
\hline $\mathrm{LDL}>130$ & 6 & 21.4 & 31 & 38.75 & $\mathrm{NS}$ \\
\hline
\end{tabular}

$\mathrm{NS}=$ Not significant association.

Thus, we analyzed whether the presence of T. forsythia is a risk factor for high levels of TC, LDL, using a linear regression model adjusted for age, gender, smoking and socioeconomic status. Likewise, whether the presence of T. forsythia is a risk factor for overweight was investigated using a logistic regression model adjusted for age, gender, BMI, smoking and socioeconomic status.

Table 4 depicts the linear models. Thus, in the simple linear model, the presence of $T$. forsythia was significantly associated with high levels of TC. In the multivariate model, this statistically significant association remained after adjustment for possible confounders. Similarly, in the simple linear model, the presence of $T$. forsythia was significantly associated with high levels of LDL. This statistically significant association also remained after adjustment for possible confounders. By use of the multivariate linear regression model, we wanted to identify explanatory factors for a difference in TC and LDL. $T$. 
Table 3. Blood lipid levels ( $\mathrm{mg} / \mathrm{dl}$; mean \pm standard deviation) in patients with or without Tannerella forsythia.

\begin{tabular}{|l|c|c|c|}
\hline Lipid & $\begin{array}{c}\text { Presence of } \\
\text { Tannerella forsythia }\end{array}$ & $\begin{array}{c}\text { Absence of } \\
\text { Tannerella forsythia }\end{array}$ & $\begin{array}{c}\boldsymbol{P} \text { value } \\
\boldsymbol{t} \text { Test }\end{array}$ \\
\hline TGs & $171.7 \pm 24$ & $163.2 \pm 25$ & NS \\
\hline HDL & $47.1 \pm 13$ & $48.4 \pm 19$ & NS \\
\hline TC & $206 \pm 33$ & $191.3 \pm 36$ & $<0.05$ \\
\hline LDL & $124.5 \pm 31$ & $110.1 \pm 37$ & $<0.05$ \\
\hline
\end{tabular}

$\mathrm{NS}=$ Not significant association

Table 4. Simple and Multivariate linear regression models for LDL and TC.

\begin{tabular}{|l|l|}
\hline Model & $\beta$ and explanatory variables \\
\hline Simple LDL & $110,179+14,290_{T f}{ }^{*}$ \\
\hline Multivariate LDL & $85,740+17,162_{T f}{ }^{*}+4,740_{\text {gender }}+0,836_{\text {age }}+19,702_{\mathrm{SE}}+5,201_{\text {smoker }}$ \\
\hline Simple TC & $191,313+14,705_{T f}{ }^{*}$ \\
\hline Multivariate TC & $167,111+17,879_{T f}{ }^{*}+1,118_{\text {gender }}+0,628_{\text {age }}-10,974_{\mathrm{SE}}+13,229_{\text {smoker }}$ \\
\hline \\
$\begin{array}{l}\text { Tf }=\text { Tannerella forsythia. } \\
\text { SE }=\text { socioeconomic status } \\
* P<0.05\end{array}$
\end{tabular}

forsythia came out as significant discriminating factor in the model. Therefore, T. forsythia emerged as significant explanatory of increased levels of TC and LDL.

On the other hand, in the crude logistic model, the presence of $T$. forsythia was not associated with overweight $(\mathrm{OR}=1.5,95 \% \mathrm{CI}=0.9-2.5)$.

\section{Discussion}

To our knowledge, the current investigation is the first to explore the relationship of $T$. forsythia on the levels of LDL and TC, offering supplementary evidence for the relation between periodontitis and atherosclerosis, discernable by high levels of LDL and TC in the presence of $T$. forsythia.

A conceivable method accounting for the described association between periodontitis and cardiovascular disease could be the release of bacteria, bacterial products or pro-inflammatory cytokines from the chronic periodontal lesion into the blood stream (11).

T. forsythia is frequently located cohabiting with $P$. gingivalis in subgingival dental biofilms (18), which also exerts a potential impact on systemic health. T. forsythia lipopolysaccharide (LPS) could be associated with the up-regulation of pro-inflammatory cytokines and it was revealed to stimulate their production by human macrophages, with the IL-8 secretion level of $T$. forsythia LPS being about 1.5 times the effect of $P$. gingivalis LPS (19). Besides, T. forsythia and BspA (its major surface virulence factor) augmented atherosclerotic lesion progression in ApoE-/- mice. This process may be associated with down regulation of lipid metabolism-related gene expression (20).

In the current study, robust associations between the presence of $T$. forsythia and high LDL and TC mean levels in periodontitis subjects were observed. These results are very significant since LDL is the major atherogenic lipoprotein and TC is a crude surrogate for LDL in risk assessment or in estimating early response to treatment, however it can be convenient in primary detection or long-term monitoring of responding (21). Notably, the above aspect shows the consistency of our results. Furthermore and consistently with this relevant finding, the occurrences of LDL and TC were higher in periodontitis patients compared to individuals without periodontitis 
(Table 2); similarly the mean levels also were higher in the presence of T. forsythia (Table 3). Moreover, the levels of TGs were greater in periodontitis patients compared to persons without periodontitis $(P<0.05)$. Augmentation of plasma triglycerides has been perceived principally in infection with gram-negative microorganism and these modifications are expedited by cytokines, which may be formed in the inflamed periodontal tissue (22). Our results are coherent with the conclusions of earlier studies $(11,12)$. Therefore, these results corroborate the proposition that chronic infections involving periodontitis may modify the serum lipid profile in a manner that raises the risk of atherosclerosis (8).

LDL levels were detected in 31 of 80 chronic periodontitis patients, and in 6 of 28 persons without periodontitis. Buhlin et al. (11) presented equivalent conclusions. A possible explanation for these effects could be related to Gram-negative bacteria and free LPS in the plasma originating a release of inflammatory mediators $(11,23)$. As was described previously, high LDL and TC levels in periodontitis patients with occurrence of T. forsythia were detected, but this was not the situation for periodontitis patients with presence of $P$. gingivalis. This contrast may be due to the particular pathogenic characters of the two periodontopathogens, particularly by specific LPS and BspA in T. forsythia $(24,25)$.

One additional significant conclusion of this study was that high levels of TC in periodontitis patients were significantly associated with augmented BOP $(P<0.05)$. A previous study also suggested an association between dyslipidemia and BOP (11). Comparable conclusions have been defined for the relationship gum bleeding and higher LDL cholesterol (26). Longitudinal epidemiological studies with larger and more varied samples are needed to further evaluate the relationship between periodontitis and dyslipidemia.

A limitation of this investigation is its cross-sectional approach, nevertheless, an association was observed between high mean levels of TC and LDL in the occurrence of $T$. forsythia in periodontitis patients, after adjusting for various potential confounders.

\section{Conclusions}

This investigation offers additional evidence for the association between periodontitis and atherosclerosis, marked by higher levels of TC and LDL in the presence of T. forsythia. These findings propose that the occurrence of $T$. forsythia increases the atherogenic potency of LDL and may intensify the risk for cardiovascular disease.

\section{References}

1. Kozarov E. Bacterial invasion of vascular cell types: vascular infectology and atherogenesis. Future Cardiol. 2012;8:123-38.

2. Campbell LA, Kuo CC. Chlamydia pneumoniae--an infectious risk factor for atherosclerosis? Nat Rev Microbiol. 2004;2:23-32.

3. Spahr A, Klein E, Khuseyinova N, Boeckh C, Muche R, Kunze M, et al. Periodontal infections and coronary heart disease: role of perio- dontalbacteria and importance of total pathogen burden in the Coronary Event and Periodontal Disease (CORODONT) study. Arch Intern Med. 2006;166:554-9.

4. Chapple IL, Wilson NH. Manifesto for a paradigm shift: periodontal health for a better life. Br Dent J. 2014;216:159-62.

5. Figuero E, Sanchez-Beltran M, Cuesta-Frechoso S, Tejerina JM, del Castro JA, Gutiérrez JM, et al. Detection of periodontal bacteria in atheromatous plaque by nested polymerase chain reaction. J Periodontol. 2011;82:1469-77.

6. Amano A, Chen C, Honma K, Li C, Settem RP, Sharma A. Genetic characteristics and pathogenic mechanisms of periodontal pathogens. Adv Dent Res. 2014;26:15-22.

7. Nonnenmacher C, Stelzel M, Susin C, Sattler AM, Schaefer JR, Maisch B, et al. Periodontal microbiota in patients with coronary artery disease measured by real-time polymerase chain reaction: a casecontrol study. J Periodontol. 2007;78:1724-30

8. Losche W, Karapetow F, Pohl A, Pohl C, Kocher T. Plasma lipid and glucose levels in patients with destructive periodontal disease. J Clin Periodontol. 2000;27:537-41.

9. Katz J, Flugelman MY, Goldberg A, Helft M. Association between periodontal pockets and elevated cholesterol and low density lipoprotein cholesterol levels. J Periodontol. 2002;73:494-500.

10. Tu YK, D’Aiuto F, Lin HJ, Chen YW, Chien KL. Relationship between metabolic syndrome and diagnoses of periodontal diseases among participants in a large Taiwanese cohort. J Clin Periodontol. 2013;40:994-1000.

11. Buhlin K, Gustafsson A, Pockley G, Frostegard J, Klinge B. Risk factors for cardiovascular disease in patients with periodontitis. Eur Heart J. 2003;24:2099-107.

12. Pussinen PJ, Jauhiainen M, Vilkuna-Rautiainen T, Sundvall J, Vesanen M, Mattila K, et al. Periodontitis decreases the antiatherogenic potency of high density lipoprotein. J Lipid Res. 2004;45:139-47.

13. Minagawa K, Iwasaki M, Ogawa H, Yoshihara A, Miyazaki H. Relationship between metabolic syndrome and periodontitis in 80-yearold Japanese subjects. J Periodont Res. 2015;50:173-9.

14. Eke PI, Page RC, Wei L, Thornton-Evans G, Genco RJ. Update of the case definitions for population-based surveillance of periodontitis. J Periodontol. 2012;83:49-54.

15. Expert Panel on Detection, Evaluation, and Treatment of High Blood Cholesterol in Adults. JAMA. 2001;285:2486-97.

16. Ashimoto A, Chen C, Bakker I, Slots J. Polymerase chain reaction detection of 8 putative periodontal pathogens in subgingival plaque of gingivitis and advanced periodontitis lesions. Oral Microbiol Immunol. 1996;11:266-73.

17. Monteiro AM, Jardini MAN, Alves S, Giampaoli V, Aubin EC, Figueiredo Neto AM, et al. Cardiovascular disease parameters in periodontitis. J Periodontol. 2009;80:378-88.

18. Socransky SS, Haffajee AD, Cugini MA, Smith C, Kent RL Jr. Microbial complexes in subgingival plaque. J Clin Periodontol. 1998;25:134-44.

19. Tan Y, Kagan JC. A cross-disciplinary perspective on the innate immune responses to bacterial lipopolysaccharide. Mol Cell. 2014;54:212-23.

20. Lee HR, Jun HK, Choi BK. Tannerella forsythia BspA increases the risk factors for atherosclerosis in ApoE-/- mice. Oral Dis. 2014;20:803-8.

21. Cooper GR, Myers GL, Smith J, Schlant RC. Blood lipid measurements: variations and practical utility. JAMA. 1992;267:1652-60.

22. Vieira CL, Cury PR, Miname MH, Martinez LR, Bortolotto LA, Giuliano IB, et al. Severe periodontitis is associated with diastolic blood pressure elevation in individuals with heterozygous familial hypercholesterolemia: a pilot study. J Periodontol. 2011;82:683-8.

23. Wendel M, Paul R, Heller AR. Lipoproteins in inflammation and sepsis. II. Clinical aspects. Intensive Care Med. 2007;33:25-35.

24. Sandi RM, Pol KG, Basavaraj P, Khuller N, Singh S. Association of Serum Cholesterol, Triglyceride, High and Low Density Lipoprotein (HDL and LDL) Levels in Chronic Periodontitis Subjects with Risk for Cardiovascular Disease (CVD): A Cross Sectional Study. J Clin Diagn Res. 2014;8:214-6. 
25. Iacopino AM, Cutler CW. Pathophysiological relationships between periodontitis and systemic disease. Recent concepts involving serum lipids. J Periodontol. 2000;71:1375-84.

26. Vedin O, Hagström E, Gallup D, Neely ML, Stewart R, Koenig $\mathrm{W}$, et al. Periodontal disease in patients with chronic coronary heart disease: Prevalence and association with cardiovascular risk factors. Eur J Prev Cardiol. 2014 Apr 10. [Epub ahead of print]

Acknowledgements

This study was supported by a grant from the Institute of Science and Technology, Francisco José de Caldas-COLCIENCIAS (No. 1308459-21661).

\section{Conflict of Interest}

The authors have no conflicts of interest to declare. 